This is the author's final, peer-reviewed manuscript as accepted for publication. The publisher-formatted version may be available through the publisher's web site or your institution's library.

\title{
Chromium oxide loaded silica aerogels: novel visible light photocatalytic materials for environmental remediation
}

Manindu N. Peiris Weerasinghe, Kenneth J. Klabunde

\section{How to cite this manuscript}

If you make reference to this version of the manuscript, use the following information:

Peiris Weerasinghe, M. N., \& Klabunde, K. J. (2013). Chromium oxide loaded silica aerogels: Novel visible light photocatalytic materials for environmental remediation. Retrieved from http://krex.ksu.edu

\section{Published Version Information}

Citation: Peiris Weerasinghe, M. N., \& Klabunde, K. J. (2013). Chromium oxide loaded silica aerogels: Novel visible light photocatalytic materials for environmental remediation. Journal of Photochemistry and Photobiology A: Chemistry, 254, 62-70.

Copyright: @ 2013 Elsevier B.V.

Digital Object Identifier (DOI): doi:10.1016/j.jphotochem.2013.01.002

Publisher's Link: http://www.sciencedirect.com/science/article/pii/S1010603013000051

This item was retrieved from the K-State Research Exchange (K-REx), the institutional repository of Kansas State University. K-REx is available at http://krex.ksu.edu 
Chromium Oxide loaded Silica Aerogels: Novel Visible light Photocatalytic Materials for

\author{
Environmental Remediation
}

Manindu N Peiris Weerasinghe, Kenneth J Klabunde

\begin{abstract}
Various photocatalytic systems have been reported for degradation of harmful air pollutants. Most of the reported catalysts are based on well-known semiconducting material, Titanium Dioxide $\left(\mathrm{TiO}_{2}\right)$, while some are based on other materials such as Silicon Dioxide $\left(\mathrm{SiO}_{2}\right)$, various Zeolites. However, titania based systems are very popular in this regard and the most of the photocatalytic processes that involve titania are considered non-localized.
\end{abstract}

Thus, to study the photocatalytic ability of a localized system, novel aerogel based samples were studied using silica and chromium and tested for photocatalytic activities. The new photocatalytic systems were prepared to obtain aerogel silica as the matrix material by cohydrolyzing silica precursor with chromium(III) ions to obtain chromium loaded silica materials. Later, these prepared samples were compared to chromium loaded titania and mixed silica-titania systems. All the prepared systems have high surface areas compared to the systems that have been reported in literature. Samples were characterized by X-ray diffraction, Diffusive reflectance UV spectroscopy, and BET surface analysis methods. The kinetics of photocatalytic degradation of a model pollutant, acetaldehyde, was performed using a Shimadzu GCMS-QP 5000 instrument and a glass reactor with a quartz window.

Change in photocatalytic activity was found with various molar ratios of $\mathrm{SiO}_{2}$ to $\mathrm{TiO}_{2}$. From all the systems, chromium loaded pure $\mathrm{SiO}_{2}$ showed the highest activity towards acetaldehyde degradation compared to mixed systems and $\mathrm{TiO}_{2}$ based systems. The interesting 
photocatalytic activity of silica based materials occurs due to the efficient insertion of chromium ions into silica matrix to generate reactive sites. The photo excitation is believed to occur at molecular orbital level at localized chromium sites.

\section{Key Words}

Photocatalysis; Aero gel; Semiconductors; Silicon Dioxide; Kinetics; Transition metal incorporation; UV and Visible light 


\section{Introduction}

Photocatalysis has been studied actively during the last several decades because of its application to green energy and due to the understanding of the importance of a cleaner atmosphere. As a result there are a large number of reports about applications of photocatalysis in various tasks such as environmental remediation, photocatalytic water splitting, etc. Photocatalysis has widely been studied to destroy organic dye compounds from industrial effluents, oxidation of indoor and outdoor organic pollutants, etc. The basic advantage of photocatalysis is its ability to mineralize a large variety of harmful organic pollutants under ambient temperature and pressure conditions. $^{[1]}$

In most of the successful photocatalytic materials that have been reported earlier, comes with a supporting base material. Titania is one of the most widely used photocatalytic material that has shown success in organic material decomposition. It is believed that the supporting material facilitates the catalytic activity of the catalytic site by enhancing charge carrier separation, allowing reduced electron hole recombination and facilitating charge transfer to adsorbed species making photocatalytic processes are non-localized. ${ }^{[2,3,4]}$ But, whether a photocatalytic process must always be non-localized and semiconductors are required are questions that still needs to be answered.

Therefore, our main objective is to discover photocatalytic systems which progress according to localized mechanisms. The study was carried out by preparing such a system using insulating silica materials. Generally low reactivity and higher band gap energy of silica makes it a suitable material to study the localized properties of photocatalysis. 
Furthermore, to achieve visible light activity, it is important to insert a suitable light harvesting material into silica in order to introduce photocatalytic activities. Transition metals and metal oxides have been actively used in this regard. Transition metals are very good candidates to absorb in the visible range of the spectrum, as orbital energy transfer usually lies in the visible range. According to several literature reports and based experiments which were carried out in our lab, chromium loaded systems showed highest activities towards oxidation of organic air pollutants. Thus, for our systems chromium was chosen as the doping agent for our more in-depth study of $\mathrm{Cr}-\mathrm{SiO}_{2}$ and mixed $\mathrm{TiO}_{2}-\mathrm{SiO}_{2}$ samples. ${ }^{[5,6,7,8]}$ Herein we report the observed UV and visible light activities of chromium ions loaded silica and titania based materials and possible mechanisms for the observed photocatalytic performances.

\section{Material and methods}

\subsection{Photocatalyst Preparation}

\subsubsection{Preparation of Chromium ions loaded Silica and/or Titania Aerogel Samples}

Chromium ion loaded silicon dioxide (Silica), titanium dioxide (Titania) and mixed silicatitania samples with varying molar ratios of silica to titania were prepared using an aerogel preparation method. During the synthesis process Tetraethylorthosilicate (TEOS) and Titaniumisopropoxide $\left(\mathrm{Ti}(\mathrm{ipr})_{4}\right)$ were used as corresponding silica and titania precursors respectively. These precursors were co-hydrolyzed in the presence of Chromium(III) nitrate $\left(\mathrm{Cr}\left(\mathrm{NO}_{3}\right)_{3} \cdot 9 \mathrm{H}_{2} \mathrm{O}\right)$, which is the chromium ion precursor. All the chemicals were analytical grade used without further purification. During the preparation of samples an amount equivalent to 0.1 mole percent of the dopant material was dissolved in $140 \mathrm{ml}$ of methanol and $20.0 \mathrm{ml}$ of TEOS solution and stirred well. Corresponding titania based samples were prepared using the same amount of chromium(III) nitrate dissolved in $140 \mathrm{ml}$ of methanol and $26.6 \mathrm{ml}$ of Ti(ipr) $)_{4}$. Mixed 
silica and titania samples were prepared using corresponding silica and titania precursor amounts for the molar ratios expected for the final products. Then, a mixture of $0.5 \mathrm{ml}$ of water and $2.5 \mathrm{ml}$ concentrated nitric acid was added drop wise to hydrolyze silica and/or titania precursors. The solution mixture was then aged for about 15 minutes and super critical drying was carried out in an autoclave. Then the autoclave was quickly vented soon after the temperature reached $265^{\circ} \mathrm{C}$. Finally, the resulting powder was calcined in air at $500^{\circ} \mathrm{C}$ for 2 hours.

\subsection{Kinetic Studies of photocatalytic systems}

Prepared samples were tested for both UV light and visible light photocatalytic activities. Kinetics of the photocatalytic degradation was studied using a Shimadzu GCMS-QP 5000 instrument and a glass reactor with a quartz window. Acetaldehyde was used as a model pollutant and the temperature of the glass reactor was maintained at $25{ }^{\circ} \mathrm{C}$ by circulating water in the outer jacket of the reactor during all the kinetic experiments. In a typical experiment $0.10 \mathrm{~g}$ of the prepared sample was uniformly placed on the special glass chamber allowing UV or visible light to directly contact the prepared photocatalytic material. Then the air filled system was sealed and $0.10 \mathrm{ml}$ of liquid acetaldehyde was introduced to the bottom of the reactor to avoid any direct contact of liquid acetaldehyde and the photocatalytic material. During the experiment acetaldehyde slowly gets evaporated due to its near room temperature boiling point, and gaseous acetaldehyde gets absorbed on to the reaction sites of the catalyst. Photocatalysts were then illuminated with UV or visible light using a $1000 \mathrm{w}$ xenon lamp and glass filters by cutting off unnecessary light. The progress of any reaction was detected by injecting $35 \mu$ l of gas samples from the sealed reactor to the Shimadzu GCMS-QP 5000 instrument every 20 minutes. All the kinetics experiments were carried out at least two times in order to confirm the accuracy 
of the results and were compared with commercially available titania P25 and prepared blank samples, where no dopant elements were present.

\subsection{Characterization Studies}

Brunauer-Emmet-Teller (BET) measurements of surface area and pore size distribution of the prepared samples were determined using a Quantachrome NOVA 1200 gas absorption/desorption analyzer after degassing the samples at $150{ }^{\circ} \mathrm{C}$ for two hours. Powder XRD analysis of the samples was carried out to determine the crystalline nature using a ScintagXDS-2000 spectrometer with $\mathrm{Cu} \mathrm{K} \alpha$ radiation with applied voltage of $40 \mathrm{kV}$ and current of 40 $\mathrm{mA}$. Samples were scanned $2 \theta$ from $0^{\circ}$ to $75^{\circ}$ with a scan rate of $1^{\circ}$ per minute. Diffuse reflectance UV-Visible spectra were measured at room temperature in air on a Cary 500 scan UV-Vis-NIR photometer over the range from 200 to $900 \mathrm{~nm}$. The sample cell was made of two transparent $\mathrm{CaF}_{2}$ discs, a Teflon O-ring and screw-type combination in which photocatalysts were packed between two discs and the O-ring. Polytetrafluoroethylene (PTFE) powder of $1 \mu \mathrm{m}$ particle size was taken as a reference material for diffuse reflectance studies.

The compositions of prepared photocatalysts were determined by carrying out elemental analysis using Energy Dispersive Spectrometry using a Scanning Electron Microscope. Detailed study of the loaded chromium was carried out using a bulk elemental analysis to determine the final amounts of loaded ions. Bulk elemental analysis was carried out using simultaneous optical systems and axial or radial viewing of the plasma using Perkin Elmer Optima 5300 spectrometer at Galbraith laboratories Inc.

TEM studies were carried out using a Philips CM100 operating at $100 \mathrm{kV}$. The TEM samples were prepared by dispersing few milligrams of the catalyst in ethanol using an ultrasonic bath. 
Then a drop of catalyst-ethanol mixture was placed on the TEM grid and air dried. The facilities were provided by the Microscopy and Analytical Imaging Laboratory at Department of Biology, Kansas State University.

\subsection{Hydroxyl radical generation studies using Terephthalic acid}

Terephthalic acid(TPA), which is not a fluorescent compound, gives a single, fluorescent product, 2-hydroxyterephthalic acid (HTPA), by reacting with hydroxyl radicals produced during the photocatalytic reaction (Figure 1). HTPA emits fluorescence at around $426 \mathrm{~nm}$ on the excitation of its own $312 \mathrm{~nm}$ absorption band. The measurements of the amount of $\mathrm{OH}^{*}$ were performed for the chromium loaded titania and silica based systems carrying out photocatalytic reaction by means of this TPA fluorescence probe method as follows. For the measurements of any hydroxyl radicals generated during photocatalytic reactions the photocatalyst samples were irradiated under UV and visible light in terephthalic acid solution $\left(2 \times 10^{-3} \mathrm{M}\right)$. Then the solution, after separation from the photocatalyst, was taken for fluorescence analysis. The fluorescence measurements were carried out at the excitation wavelength of $314 \mathrm{~nm}$ in the range of emission wavelength from $330 \mathrm{~nm}$ to $600 \mathrm{~nm}$ with maximum peak at $425 \mathrm{~nm} \cdot{ }^{[9,10,11]}$

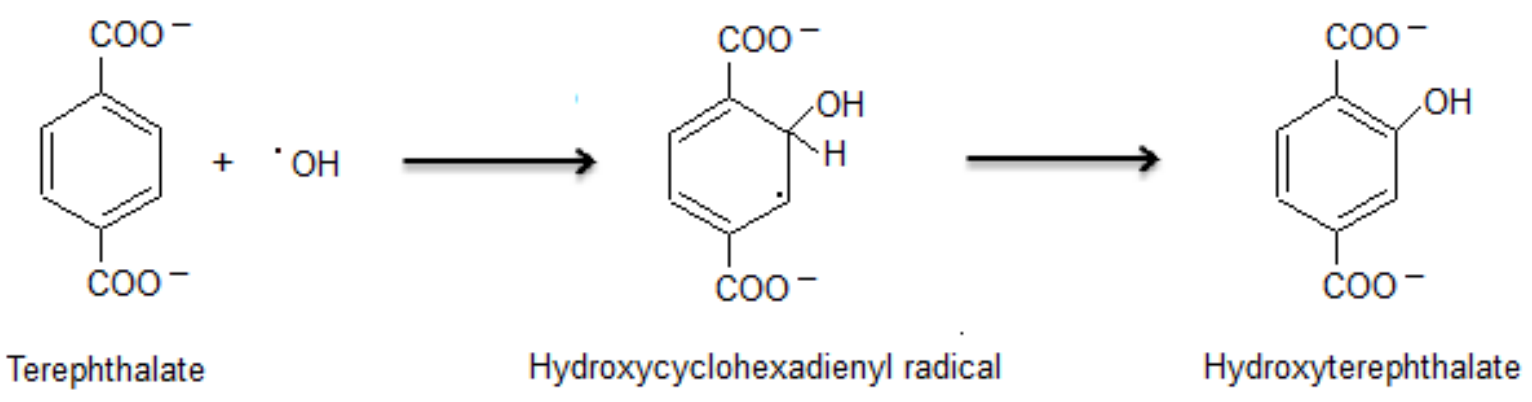

Figure 1: Reaction path of terephthalate and hydroxyl radicals to generate fluorescent hydroxyterephthalate 


\section{Results and Discussion}

\subsection{Structure of Chromium loaded Photocatalytic systems}

It is well-known that the effective surface area of a material is important in deciding the photocatalytic efficiency of a material because in most of the photocatalytic systems the catalytic activity takes place on the surface of the material ${ }^{[12]}$. Therefore, the photocatalyst synthesis process was specially designed to obtain higher effective surface area using a super critical drying technique. Surface area values obtained from the BET analysis experiment show that all the samples have very high effective surface area values. Obtained effective surface area values of silica based materials are higher compared to that of titania based materials which confirm what has previously been reported. ${ }^{[13,14]}$ Further, mixed silica and titania systems show a gradual decrease in effective surface area with increasing amounts of titania added as indicated in table 1. The surface area of samples increased according to a linear pattern with increasing amounts of silica (Supporting Information S1).

Table 1: Change in specific surface area of $0.5(\mathrm{~mol}) \%$ chromium loaded silica and titania based materials

\begin{tabular}{|c|c|c|c|c|c|c|c|}
\hline $\begin{array}{c}\text { Percentage } \\
\text { of Silica }\end{array}$ & 100 & 80 & 60 & 50 & 40 & 20 & 0 \\
\hline $\begin{array}{c}\text { Percentage } \\
\text { of Titania }\end{array}$ & 0 & 20 & 40 & 50 & 60 & 80 & 100 \\
\hline $\begin{array}{c}\text { Effective } \\
\text { Surface } \\
\text { Area }\left(\mathrm{m}^{2} / \mathrm{g}\right)\end{array}$ & 717 & 641 & 408 & 345 & 291 & 222 & 84 \\
\hline
\end{tabular}

According to the EDS studies the ratios of silica to titania in mixed oxide samples matched exactly to the initial precursor concentrations. But, due to the limited sensitivity of the instrument as well as the minute amount of dopants present in these samples, percentages of chromium 
could not be detected (Supporting Information, S2). Therefore, a bulk elemental analysis was carried out specially to determine the amounts of chromium present in the $0.5(\mathrm{~mol}) \%$ chromium loaded sample. According to the results obtained, the percentage of chromium is $0.369 \%$ by weight, which when converted in to reported mol $\%$ units comes around $0.43(\mathrm{~mol}) \%$. Thus, considering possible instrumental errors it is clear that only a minimal amount of chromium has been lost during the preparation procedure.

XRD patterns of the Chromium loaded photocatalytic systems are shown in Figure 2. Characteristic peaks for the anatase titania can be identified in the titania based system and the mixed titania silica systems. No crystalline peaks were observed for the rutile crystalline phase of titania. This confirms that prepared titania based samples have anatase crystallinity which is suitable for good photocatalytic performance. ${ }^{[15]}$ For the silica based system one broad peak was observed that indicates the well-known amorphous nature of silica materials.

Furthermore, no other diffraction peaks arising from loaded chromium were observed for any system indicating that chromium ion doping during the synthesis has no effect on the crystalline phase of the matrix material and the loaded chromium does not create any crystalline phases either. Chromium crystalline peaks may not be detectable due to lower concentrations and very smaller crystallite sizes. Detailed XRD studies were carried out with higher loading chromium silica samples prepared in the same procedure to study the reason for absence of chromium crystalline peaks. But, as indicated in the figure $2 \mathrm{~b}$, no crystalline peaks arising from chromium species could be recognized for any higher loaded samples. Thus, consistent with literature reports it is clear that chromium either exist as non-crystalline forms bound to silica matrix or finely dispersed in the matrix of silica or titania as very small chromium oxide nano-particles. ${ }^{[5,16]}$ 
(a)
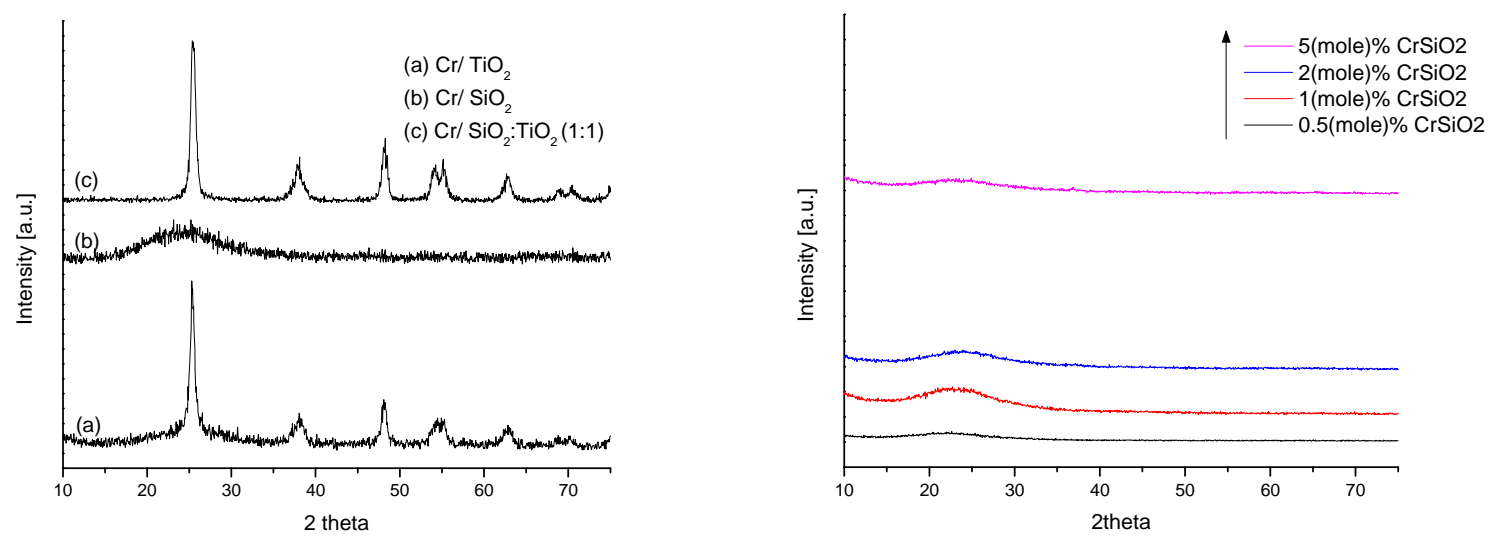

Figure 2: (a) Powder XRD studies of 0.5(mol)\% Cr loaded silica, titania and (1:1) mixed systems (b) powder XRD studies of 0.5(mol)\% $\mathrm{Cr}-\mathrm{SiO}_{2}, 1(\mathrm{~mol}) \% \mathrm{Cr}-\mathrm{SiO}_{2}, 2(\mathrm{~mol}) \% \mathrm{Cr}-$ $\mathrm{SiO}_{2}$ and $5(\mathrm{~mol}) \% \mathrm{Cr}-\mathrm{SiO}_{2}$.

Figure 3 shows diffuse reflectance UV-Vis absorption spectra of chromium loaded $\mathrm{SiO}_{2}, \mathrm{TiO}_{2}$, and mixed photocatalysts. The absorption spectra obtained for titania based samples show absorption bands in the UV region compatible with previously reported Titania P25. ${ }^{[16]}$ As expected, when chromium is present, absorption in the visible region was observed. For silica based photocatalytic systems, bands at $240 \mathrm{~nm}, 265 \mathrm{~nm}, 360 \mathrm{~nm}, 445 \mathrm{~nm}$ and $550 \mathrm{~nm}$, can be easily recognized in the system where no titania is present. The bands correspond to $\mathrm{O} \rightarrow \mathrm{Cr}^{6+}$ charge transfer transitions for $\mathrm{Cr}^{6+}$ ions in tetrahedral environment. These bands can be assigned as follows; the band at $445 \mathrm{~nm}\left(22500 \mathrm{~cm}^{-1}\right)$ is the symmetry-forbidden transition $\left(1 \mathrm{t}_{1} \rightarrow 2 \mathrm{e}\right)$ which is partially allowed in solid salts, while the other bands at $370 \mathrm{~nm}\left(27000 \mathrm{~cm}^{-1}\right) 1 \mathrm{t}_{1} \rightarrow 2 \mathrm{e}$, $294 \mathrm{~nm}\left(34000 \mathrm{~cm}^{-1}\right) 1 \mathrm{t}_{1} \rightarrow 7 \mathrm{t}_{2}$, and $241 \mathrm{~nm}\left(41400 \mathrm{~cm}^{-1}\right) 6 \mathrm{t}_{2} \rightarrow$ 2e are symmetry allowed transitions. ${ }^{[18,19,20]}$ 


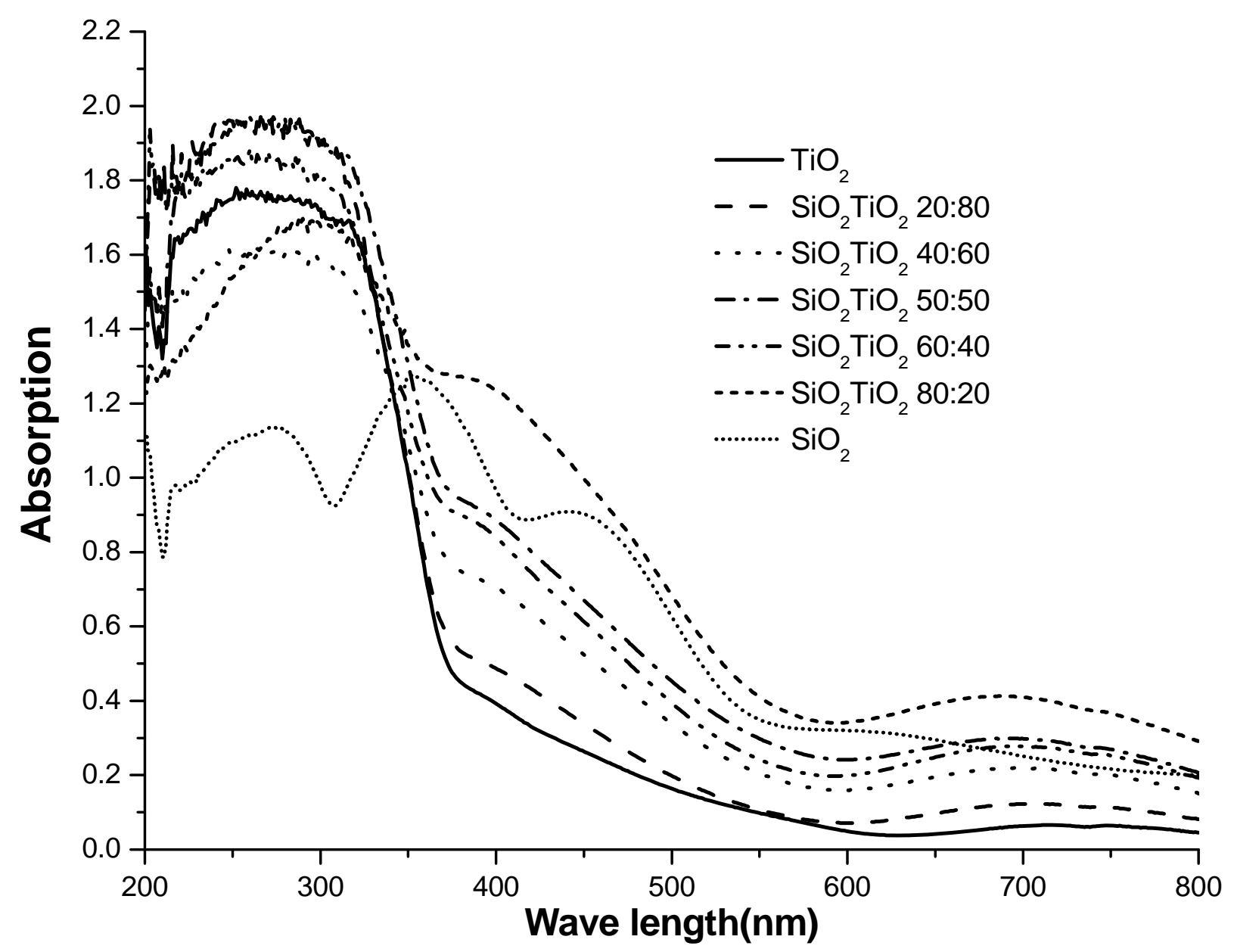

Figure 3: Variation of UV-vis absorption bands with different ratios of $\mathrm{SiO}_{2}$ to $\mathrm{TiO}_{2}$ of samples loaded with $0.5(\mathrm{~mol}) \%$ chromium

Therefore, based on the XRD and the clear UV-Vis absorption patterns which correspond to the individual $\mathrm{Cr}^{6+}$ state, it is evident that isolated $\mathrm{Cr}(\mathrm{VI})$ sites exist dispersed in the matrices of Silica and Titania. The use of minute amounts of chromium during the preparation of these materials also favor the formation of isolated $\mathrm{Cr}^{6+}$ sites. ${ }^{[5]}$ Tetrahedral $\mathrm{Cr}^{6+}$ has been reported in three different chemical forms, such as Chromium oxide $\left(\mathrm{CrO}_{3}\right)$, Chromate ions $\left(\mathrm{CrO}_{4}{ }^{2-}\right)$ and Dichromate ions $\left(\mathrm{Cr}_{2} \mathrm{O}_{7}{ }^{2-}\right)$. Due to the characteristic yellow-orange coloration and according to previous reports both chromate and dichromate species are possible on silica surface ${ }^{[21]}$. 

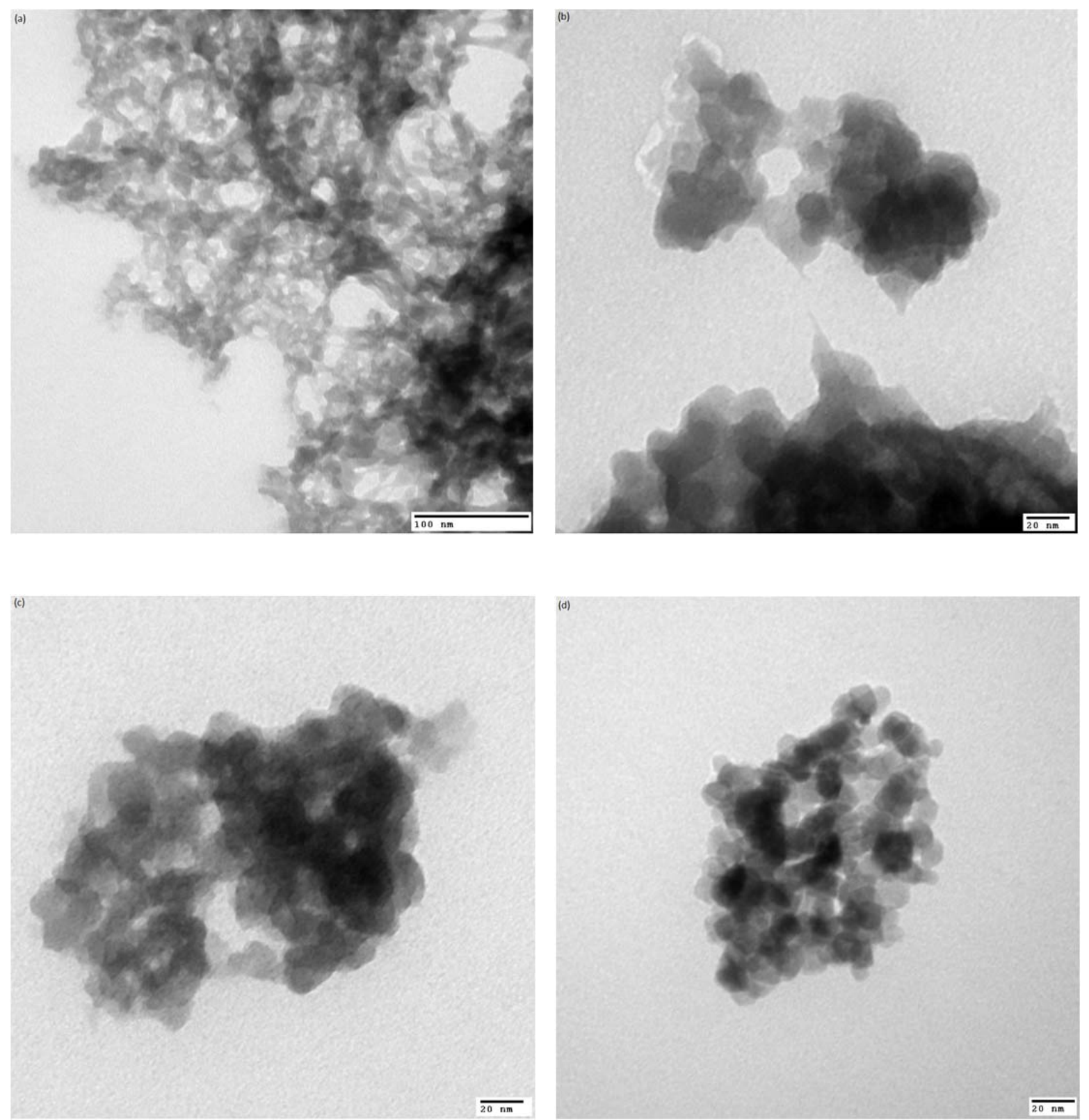

Figure 4: TEM images of (a) Blank Silica aerogel, (b) 0.5(mol) \% $\mathrm{Cr}-\mathrm{SiO}_{2}$ catalyst (c) $5(\mathrm{~mol}) \%$ $\mathrm{Cr}-\mathrm{SiO}_{2}$, and (d) 0.5(mol) \% $\mathrm{Cr}-\mathrm{TiO}_{2}$

Comparison of TEM images of blank silica sample, $0.5(\mathrm{~mol}) \% \mathrm{Cr}_{-} \mathrm{SiO}_{2}$, and $5(\mathrm{~mol}) \% \mathrm{Cr}-$ $\mathrm{SiO}_{2}$ is shown in figure 4 above. Loaded chromium sites on silica matrix can be identified in both chromium loaded samples as $\sim 2 \mathrm{~nm}$ size dark spots. The amount of chromium sites increase with increasing chromium loading was observed without significant increase in the size 
of these particles. But, no chromium sites could be observed on the surface of $\mathrm{Cr}-\mathrm{TiO}_{2}$ sample as shown in the figure $4 \mathrm{~d}$.

The structure of the bound chromium site is one of the important factors when studying the mechanism of photocatalytic action. There have been several attempts reported in literature to characterize the structure of isolated $\mathrm{Cr}^{6+}$ sites on silica. Moisii and co-workers proposed two possible structures for $\mathrm{Cr}^{6+}$ sites (Scheme 1a and $1 \mathrm{~b}$ ) and confirmed the structure 1a for their $0.5 \%$ Cr loaded silica xerogels using XANES and Raman spectroscopic studies. ${ }^{[22]}$
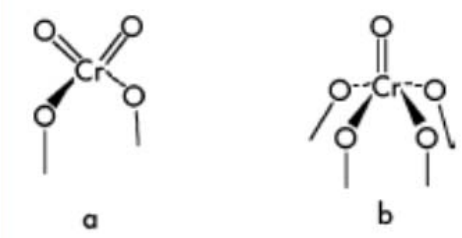

\section{Scheme 1: possible structures for the bonding nature of chromium sites to silica}

The probability of getting the same binding nature for our $0.5(\mathrm{~mol}) \%$ chromium loaded silica system is high due to the similar compositions and nearly same synthesis procedures that were employed during the preparation of materials. Further, it has been predicted in literature, using Pauling's criterion, that there is a high probability of isomorphous substitution, which would yield metal ions in a stable tetrahedral environment surrounded by oxygen atoms. Based on the ratio of ionic radii, $\rho$, of the cation and anion, the calculated value for titania and oxygen ( $\rho=0.515)$ falls out of the acceptable range $(\rho=0.225-0.414)$ for a tetrahedral coordination due to the larger size of $\mathrm{Ti}^{4+}(68 \mathrm{pm})$. Therefore, the binding of small tetrahedral $\mathrm{Cr}^{6+}(44 \mathrm{pm})$ ions to titania matrix is unlikely due to the larger distortion. But Since the ionic radii of $\mathrm{Cr}^{6+}$ and $\mathrm{Si}^{4+}(41 \mathrm{pm})$ are much closer in value, binding of $\mathrm{Cr}^{6+}$ into a silica matrix is very favorable compared to $\mathrm{Cr}^{6+}$ binding onto titania. ${ }^{[25]} \mathrm{But}$, due to the presence of the hexavalent Cr oxidation state in our catalyst, it is unlikely that $\mathrm{Cr}^{6+}$ could enter into the bulk lattice of silica due to charge 
considerations and due to the absence of four siloxy anions. Thus, it is likely that most of the loaded chromium will end up on the surface of the silica material about 1-2 nm sized clusters of chromium(VI) oxide, resulting in a large number of catalytically active sites. ${ }^{[22,23]}$

\subsection{Kinetics of photocatalytic degradation}

Figure 5 summarizes the results obtained from acetaldehyde photodegradation studies of prepared silica, titania and mixed photocatalytic systems under UV and Visible light.

(a)

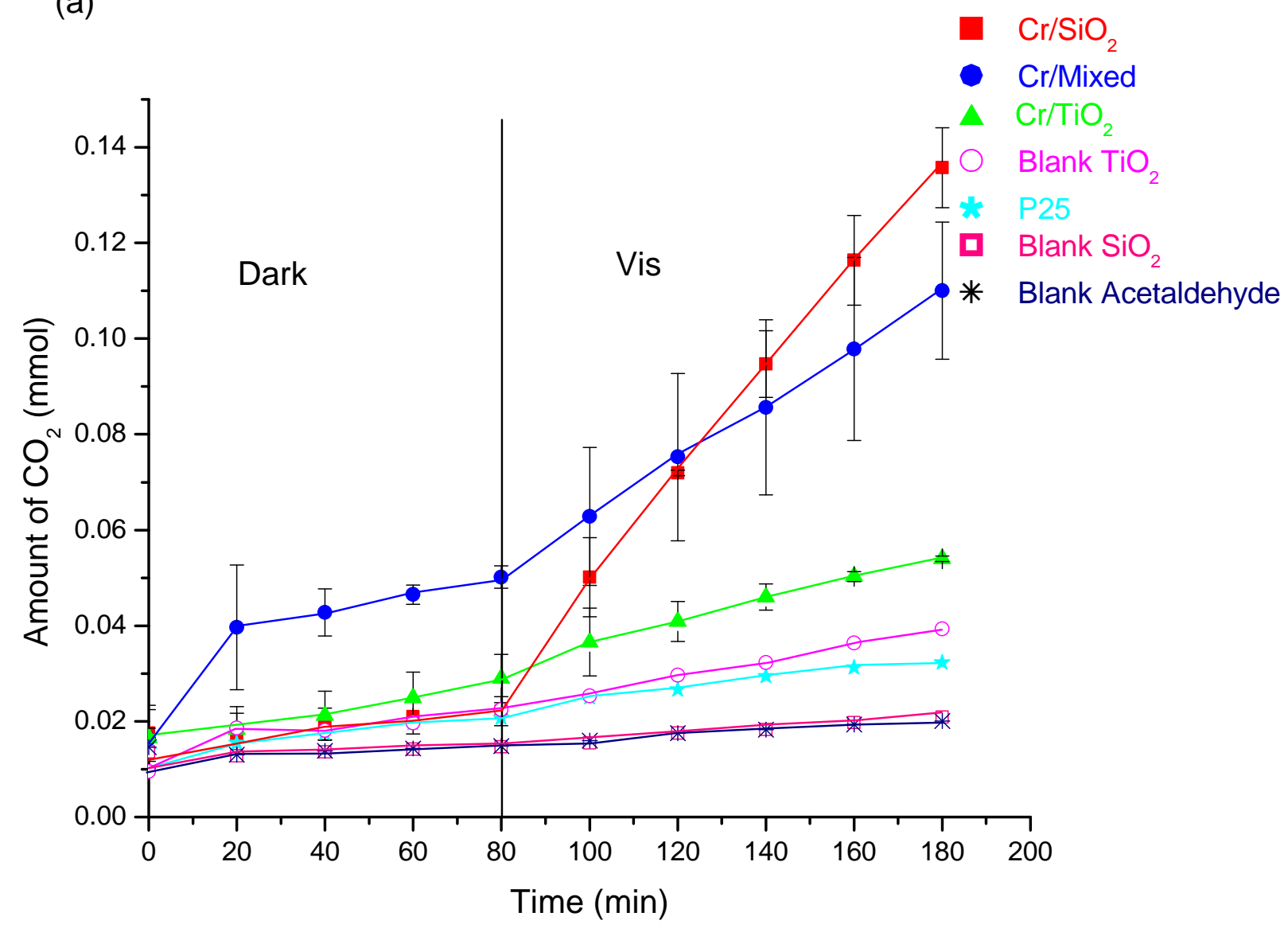


(b)

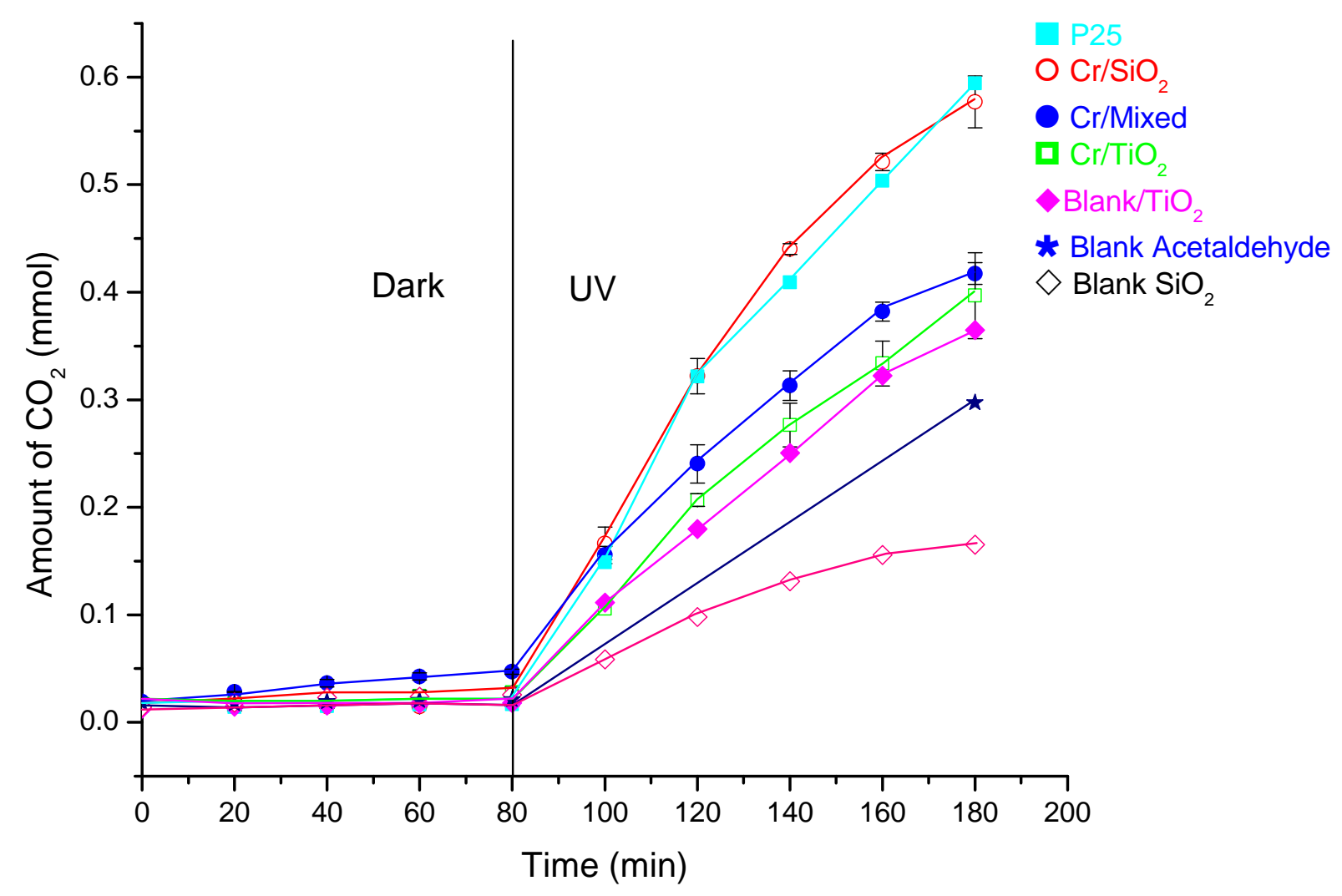

Figure 5: Kinetics of photocatalytic degradation of acetaldehyde using $0.5 \%(\mathrm{~mol})$ chromium loaded silica, titania, mixed systems, blank samples and commercially available titania P25 (a) under UV light irradiation (b) under visible light irradiation

According to the kinetic results obtained, chromium ion loaded silica shows the highest photocatalytic degradation ability towards acetaldehyde under UV and visible light. The blank silica sample, without any chromium ion doping, shows minimal acetaldehyde degradation, indicating the importance of loaded chromium in the photocatalytic performance. Furthermore, the acetaldehyde degradation under UV light without any catalyst (Blank Acetal) is higher than that of in the presence of pure silica $\left(\mathrm{Blank} / \mathrm{SiO}_{2}\right)$. Blank titania also shows significant $\mathrm{CO}_{2}$ production and this is expected for titania based compounds under UV light. ${ }^{[3,25]}$ Chromium doping seems to be not very important in UV light based catalysis as there is only a slight 
increase in the activity compared to the blank titania based sample. The highest active sample, chromium loaded silica aerogel, as shown in both figures $5 \mathrm{a}$ and $5 \mathrm{~b}$, shows very interesting photocatalytic behaviors under UV and visible wavelengths that only start its activity upon exposure to light confirming photocatalytic nature of the material.

The photocatalytic activity under visible light is of more interest to us since a larger percentage of solar radiation consists of visible range. ${ }^{[24]}$ Thus, all the samples were tested for visible light photo degradation of acetaldehyde and the results obtained are plotted in figure 5a. According to the kinetic results acetaldehyde degradation under visible light without any catalyst is very low. Therefore, it can be assumed that all the carbon dioxide observed is due to the photocatalytic behavior of the material synthesized. Blank silica sample showed no photocatalytic activity, as expected, because of the inability of insulating silicon dioxide $\left(\mathrm{SiO}_{2}\right)$ to act as a photocatalytic material by itself. The titania sample prepared in our labs shows a slight activity compared to commercially available P25 which may be arising due to the compositional changes of different crystalline phases, surface area differences and the particle sizes of titania. ${ }^{[3,25]}$ According to the powder X-ray diffraction studies (figure 2) the titania based samples prepared in our lab consisted of $100 \%$ anatase crystalline titania. But, commercially available P25 titania is a mixture of both anatase and rutile crystalline phases. ${ }^{[3,25]}$ According to earlier reports, the anatase phase is more efficient as photocatalytic material compared to that of rutile phase. Thus, the presence of more anatase titania in our samples may be responsible for the comparatively higher activity of our blank titania sample. ${ }^{[3,25]}$

The $0.5(\mathrm{~mol}) \% \mathrm{Cr}-\mathrm{SiO}_{2}-\mathrm{TiO}_{2}$ systems and the $0.5(\mathrm{~mol}) \% \mathrm{Cr}-\mathrm{SiO}_{2}$ systems show very high photocatalytic activities under visible light compared to all the other systems. Further, according to figure 6 , which compares the effect of different ratios of silica and titania on kinetic activities 
under visible light, increasing photo degradation ability is observed when more and more silica is present. This increased photo activity could occur due to the favorable binding $\mathrm{of} \mathrm{Cr}^{6+}$ in a silica matrix over that of titania.

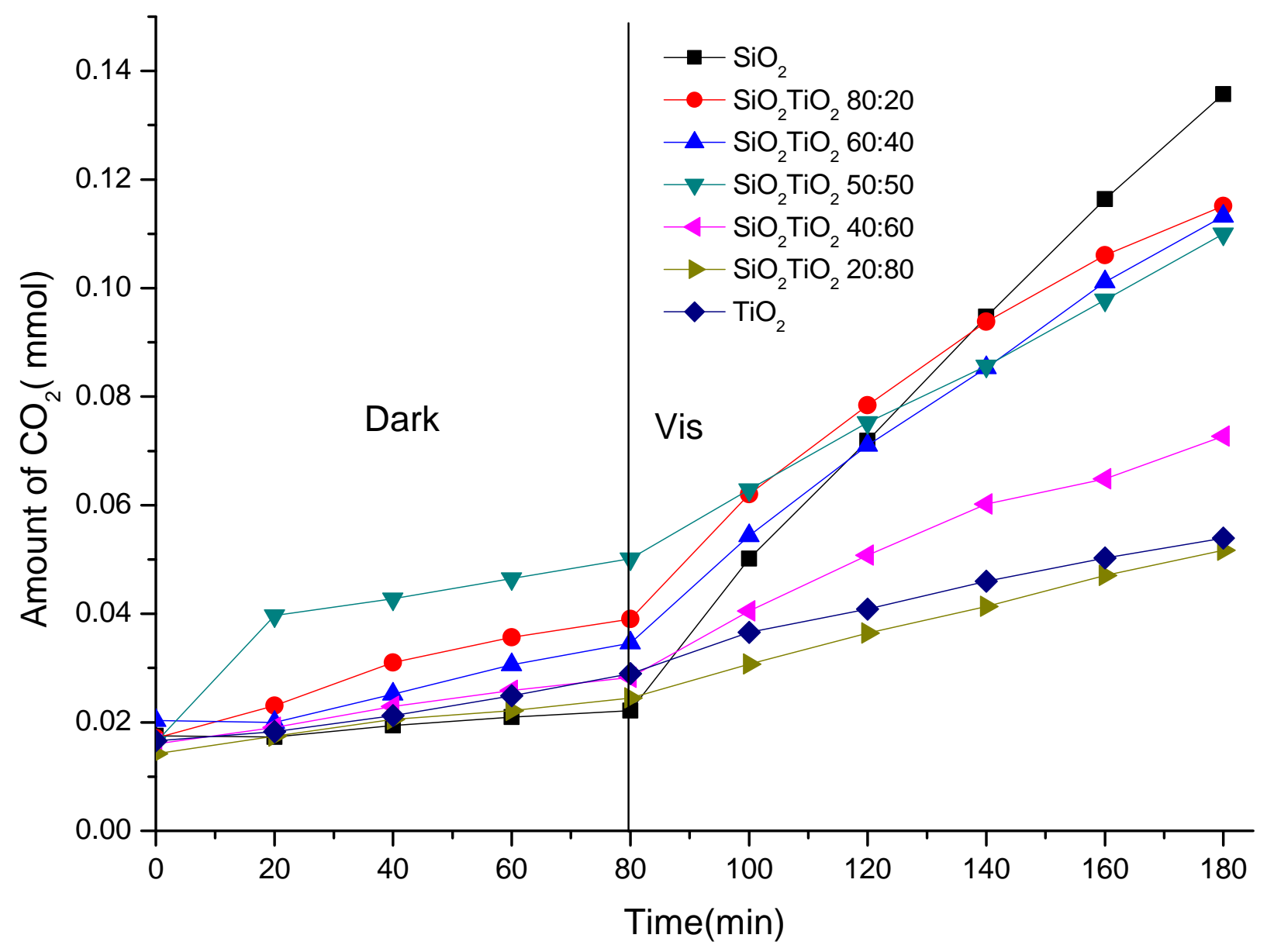

Figure 6: Kinetics of photocatalytic degradation of acetaldehyde using $0.5 \%(\mathrm{~mol})$ chromium loaded photocatalytic systems with varying ratios of $\mathrm{SiO}_{2}: \mathrm{TiO}_{2}$ under visible light irradiation

Turnover number and the rate of catalysis were calculated using kinetic information given in figure 5. For calculation purposes the amount of loaded chromium was used as the catalytic active sites assuming that all the loaded chromium involved equally in catalytic oxidation process. Turnover numbers given are only for 100 minutes of catalytic time. Since the catalysts are active after 100 minutes reaction time, turnover numbers can be further improved by carrying 
out catalytic experiments for prolonged time durations. Thus, turnover numbers for $0.5(\mathrm{~mol}) \%$ $\mathrm{Cr}-\mathrm{SiO}_{2}$ system and mixed systems clearly indicate that the acetaldehyde degradation process is photocatalytic in nature.

$$
\begin{gathered}
\text { Turnover Number }=\frac{\text { Amount of } \mathrm{CO}_{2} \text { produced }(\mathrm{mol})}{\text { Amount of the catalyst present }(\mathrm{mol})} \\
\text { Turnover Frequency }=\frac{\text { Turnover Number }}{\text { Time }}\left(\mathrm{min}^{-1}\right)
\end{gathered}
$$

Table 2: Turnover numbers obtain for the acetaldehyde degradation under visible light

\begin{tabular}{|c|c|c|}
\hline Catalyst & $\begin{array}{c}\text { Turnover Number } \\
\text { (First 4 hours of } \\
\text { catalysis })\end{array}$ & $\begin{array}{c}\text { Turnover } \\
\text { Frequency }\left(\mathrm{min}^{-1}\right)\end{array}$ \\
\hline $0.5(\mathrm{~mol}) \%{\mathrm{Cr}-\mathrm{SiO}_{2}}^{-17}$ & 11 & 0.17 \\
\hline $0.5(\mathrm{~mol}) \% \mathrm{Cr}-\mathrm{SiO}_{2}-\mathrm{TiO}_{2}(80: 20)$ & 12 & 0.11 \\
\hline $0.5(\mathrm{~mol}) \% \mathrm{Cr}-\mathrm{SiO}_{2}-\mathrm{TiO}_{2}(60: 40)$ & 8.8 & 0.12 \\
\hline $0.5(\mathrm{~mol}) \% \mathrm{Cr}-\mathrm{SiO}_{2}-\mathrm{TiO}_{2}(50: 50)$ & 6.5 & 0.07 \\
\hline $0.5(\mathrm{~mol}) \% \mathrm{Cr}-\mathrm{SiO}_{2}-\mathrm{TiO}_{2}(40: 60)$ & 4.0 & 0.04 \\
\hline $0.5(\mathrm{~mol}) \% \mathrm{Cr}-\mathrm{SiO}_{2}-\mathrm{TiO}_{2}(20: 80)$ & 3.7 & 0.04 \\
\hline $0.5(\mathrm{~mol}) \% \mathrm{Cr}_{-}-\mathrm{TiO}_{2}$ & & \\
\hline
\end{tabular}

\subsection{Mechanism/s of photocatalytic activity}

Understanding the mechanism which governs the photocatalytic activity is equally important to the study of the structure of the material, and can lead to predicting better photocatalysts. The study of hydroxyl radical generation upon exposure to UV light is widely used to confirm the 
mechanism of photocatalytic activity of titania based photo catalysts. ${ }^{[8,23]}$ The observed intense fluorescence peaks at $426 \mathrm{~nm}$ indicate the oxidation ability of the generated reactive species which we believe the main component is hydroxyl radicals according to the previous reports. The results obtained from hydroxyl radical detection experiments for both titania and silica based samples studied herein, clearly indicate the formation of hydroxyl radicals during the photocatalytic performance of silica based sample as well (figure 7).
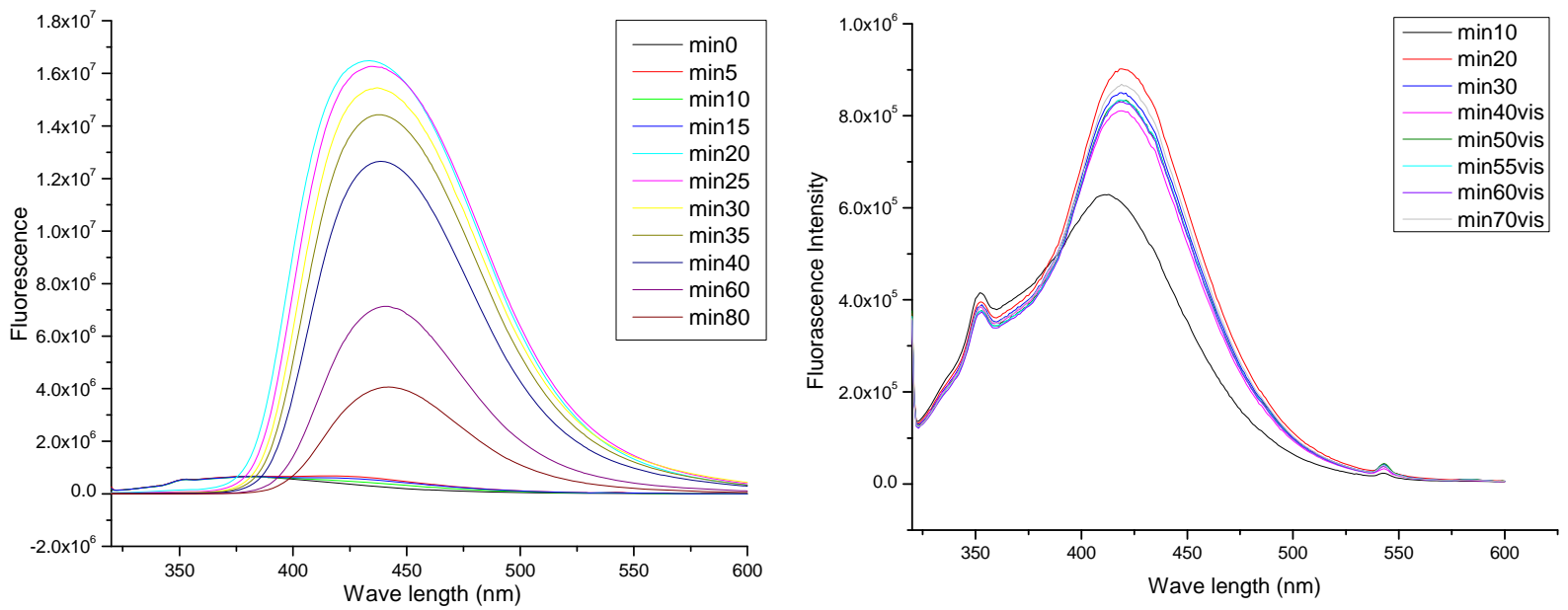

Figure 7: Fluorescence spectra obtained for the supernatant liquid of the irradiated a) titania b) silica suspension containing $3 \times 10^{-3} \mathrm{M}$ terephthalic acid at various irradiation periods.

Comparing the results of kinetic studies, it is clear that $0.5(\mathrm{~mol}) \% \mathrm{Cr}-\mathrm{SiO}_{2}$ material is able to perform best in degrading acetaldehyde into carbon dioxide. Further, according to the results obtained the catalytic activity emerges only upon irradiation of light, proving the photocatalytic nature of the catalyst. Since silica is an insulating compound with very large band gap, it cannot be excited with light photons generating reactive electron hole pairs, which is generally considered as the primary process governing any photocatalytic reaction upon exposure to UV/ Visible light. But, due to the high photo sensitivity observed in the Cr loaded silica photocatalyst, there must be a different mechanism of photocatalytic degradation. 
According to the evidence from UV-Visible spectra, TEM and XRD analysis, chromium sites in the silica matrix are highly dispersed. In addition to that, due to the insulating silica support the active photocatalytic sites, which are metal oxide species, are localized and isolated making the photocatalytic process significantly different from that of semiconducting titania.

According to Yoshida and coworkers studies, when loded metal oxides are highly dispersed a photo driven excitation can occurs at the molecular orbital level at localized reaction sites ${ }^{[6]}$ During the excitation process, an electron in the ground state of the M-O bond gets excited to an unoccupied singlet orbital. Then depending of the availability of inter system crossing mechanisms, the excited electron could transfer to a triplet state yielding phosphorescence, which has been detected using a photoluminescence spectroscopic method. ${ }^{[6]}$ We were able to observe similar emission fine structure which consist of intensity maxima corresponding to each vibrational energy level of the bond in the photoactive site, in our case $(\mathrm{Cr}-\mathrm{O})$. Note our solid state photoluminescence studies (Figure 8). According to the results indicated in the figure 9, fine structure cannot be identified in photoluminescence spectra of blank samples. The emission peaks present in the blank photoluminescence spectra may occur due to the output of the light source in the instrument as well as outside light sources. Since, the blank samples do not show any fine structures in the region where fine structure is observed for $\mathrm{Cr}-\mathrm{SiO}_{2}$ sample, it is clear that peak patterns arise due to the presence of chromium. Further, the luminescence fine structures are much clear in silica based systems compared to that of titania based system which is a good evidence for higher number of reactive sites in much reactive silica based photocatalysts. Even though we can assign this peaks generally as phosphorescence fine structure due to vibrational bands, in depth studies and calculations are necessary to confirm the 
assignment. But, in general the observed vibrational fine structure is a clear indication of the localized excitation process taking place during the photocatalytic process.

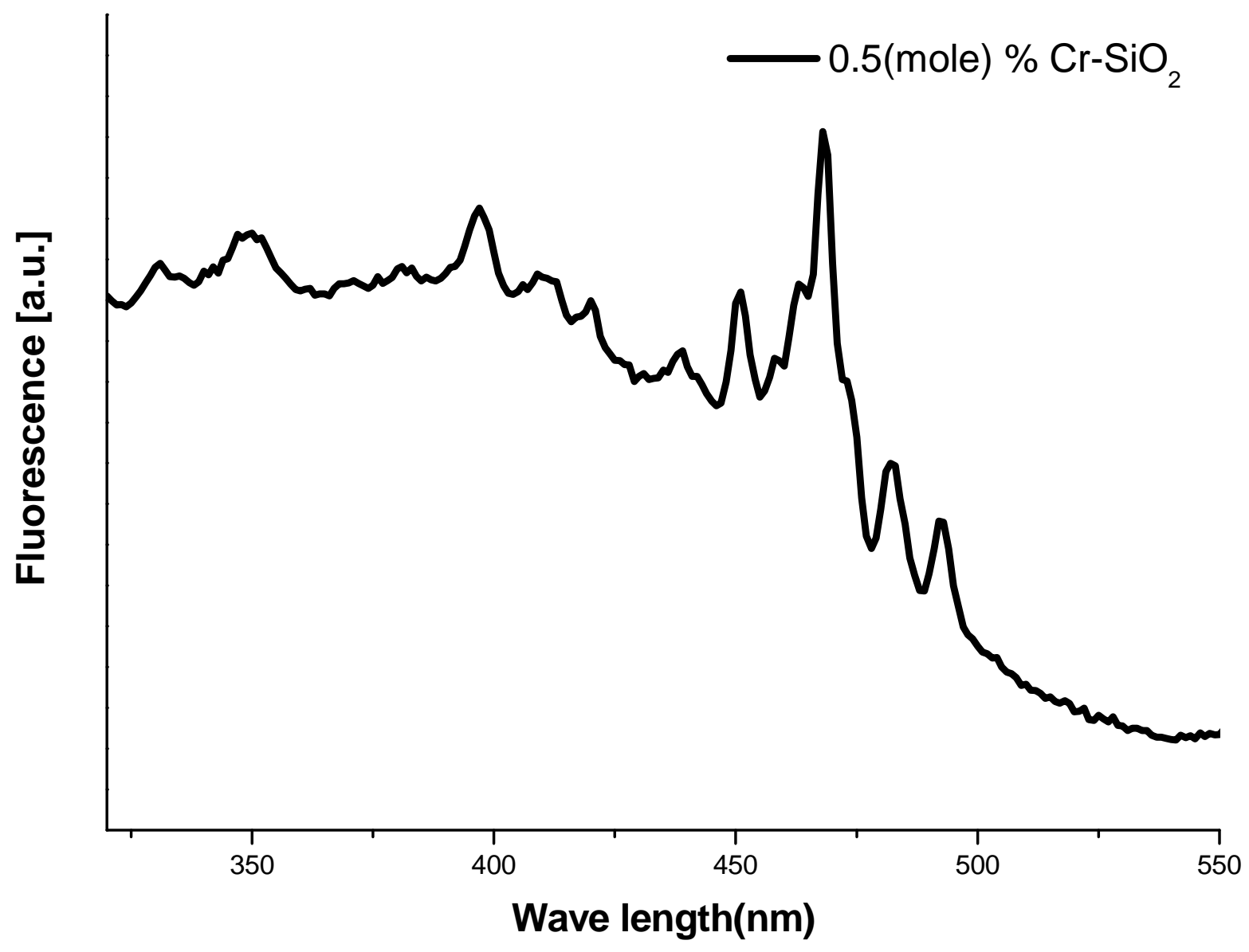

Figure 8: Solid state fluorescence of $0.5(\mathrm{~mol}) \% \mathrm{Cr}-\mathrm{SiO}_{2}$ catalyst at $300 \mathrm{~nm}$ excitation wave length 


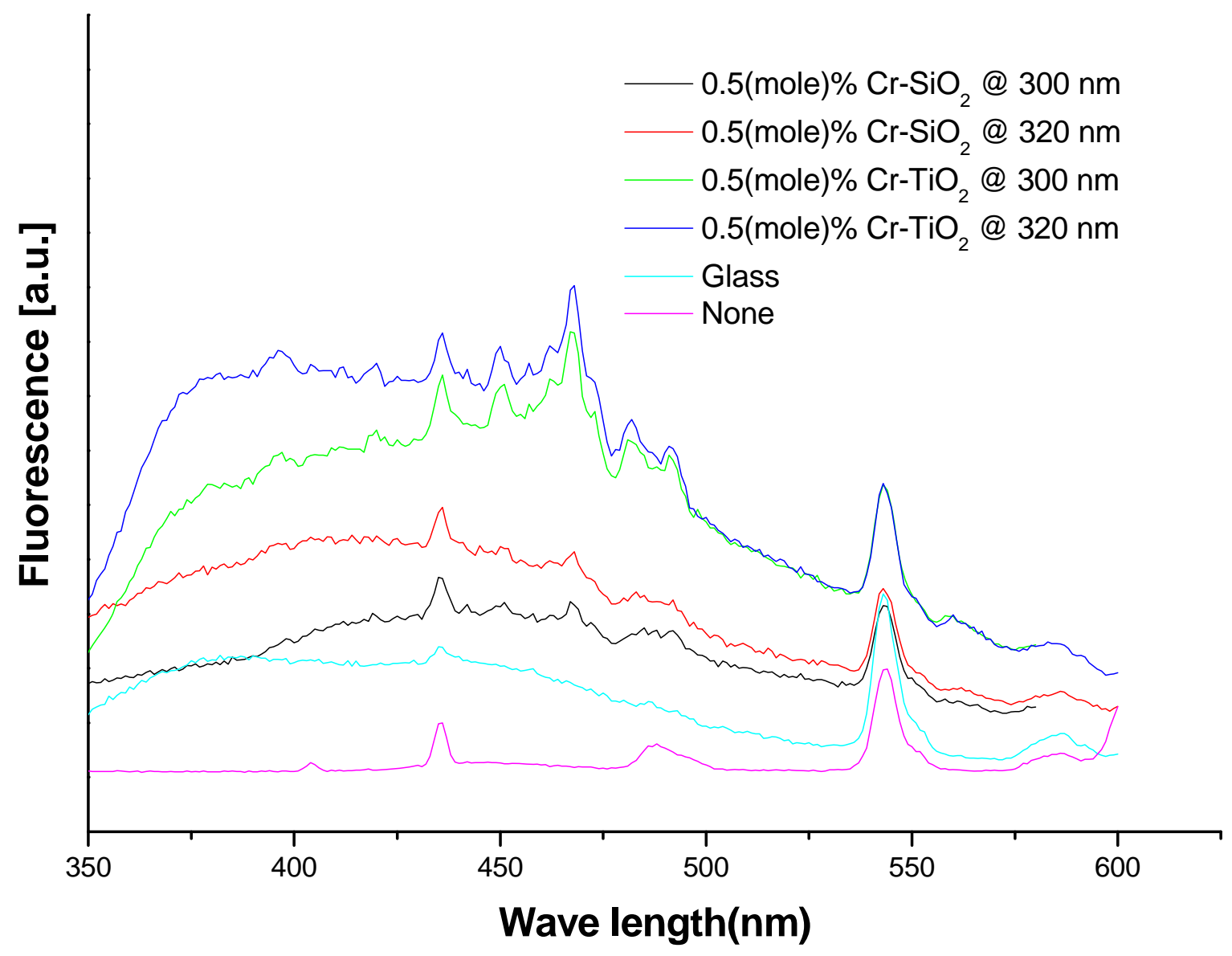

Figure 9: comparison of solid state fluorescence study of $0.5(\mathrm{~mol}) \% \mathrm{Cr}-\mathrm{SiO}_{2}, 0.5(\mathrm{~mol}) \%$ $\mathrm{Cr}-\mathrm{TiO}_{2}$ and blank samples

The intervals of peak maxima values obtained for the photoluminescence studies indicate the vibration energy of the photoactive sites. The calculated values are indicated in the table (3) below. According to the calculated values does not in agreement with the reported IR values for the $\mathrm{Cr}=\mathrm{O}$ and the $\mathrm{Cr}-\mathrm{O}-\mathrm{Si}$ bonds reported in literature, but in agreement with $\mathrm{IR}$ values of $\mathrm{Cr}-\mathrm{O}$ bonds of chromium clusters (Figure 10). ${ }^{[24-27]}$ 
Table 1: The intervals of the fine structure on the phosphorescence spectrum of $\mathrm{Cr}-\mathrm{SiO}_{2}$

\begin{tabular}{|c|c|c|}
\hline Maximum Wavelength (nm) & Maximum Wavelength (cm-1) & $\begin{array}{c}\text { Gap between adjacent peaks } \\
(\mathrm{cm}-1)\end{array}$ \\
\hline 438 & 22779.04 & - \\
\hline 451 & 22222.22 & 606.1 \\
\hline 468 & 21367.52 & 605.4 \\
\hline 483 & 20746.89 & 620.6 \\
\hline 493 & 20325.2 & 421.7 \\
\hline
\end{tabular}

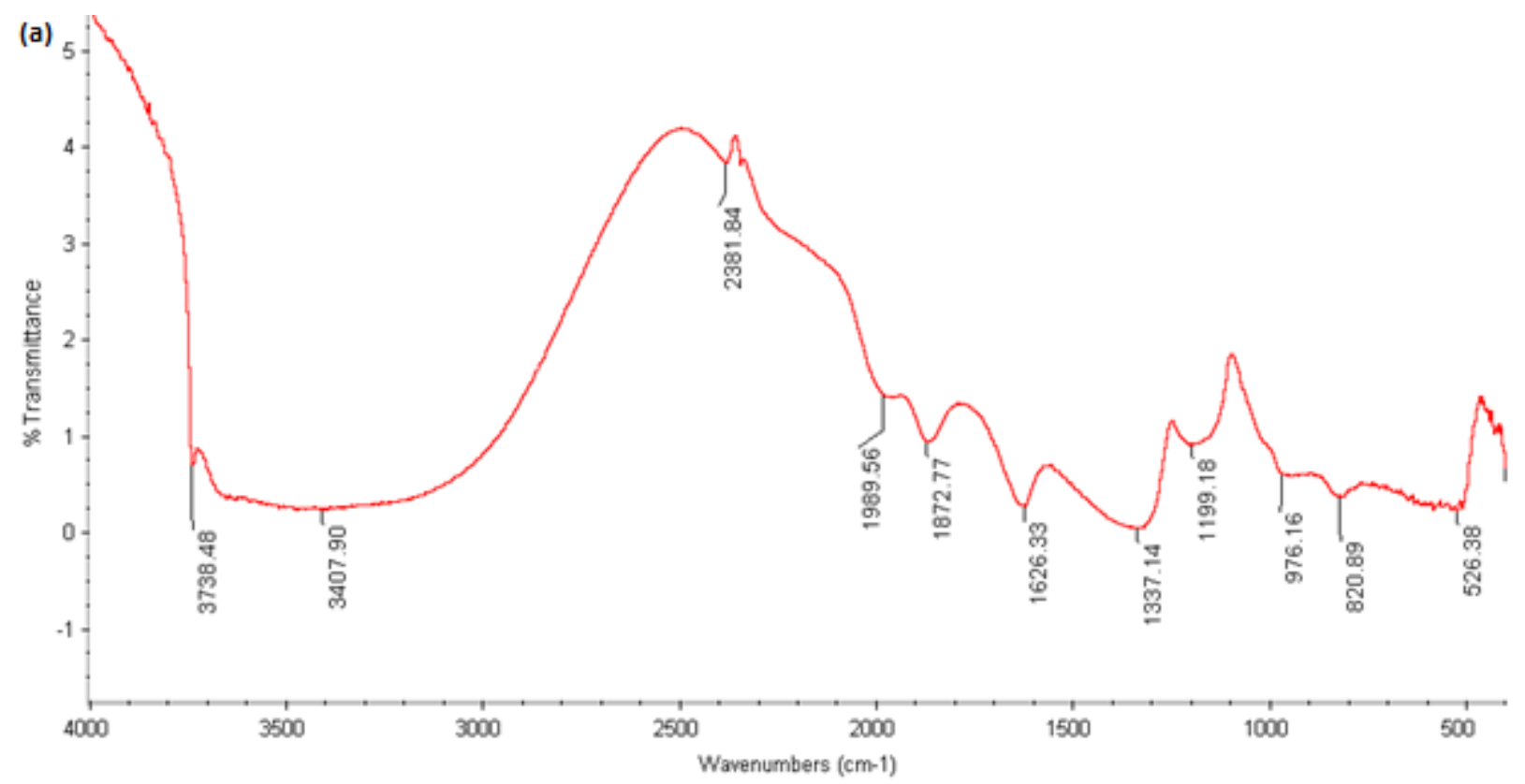




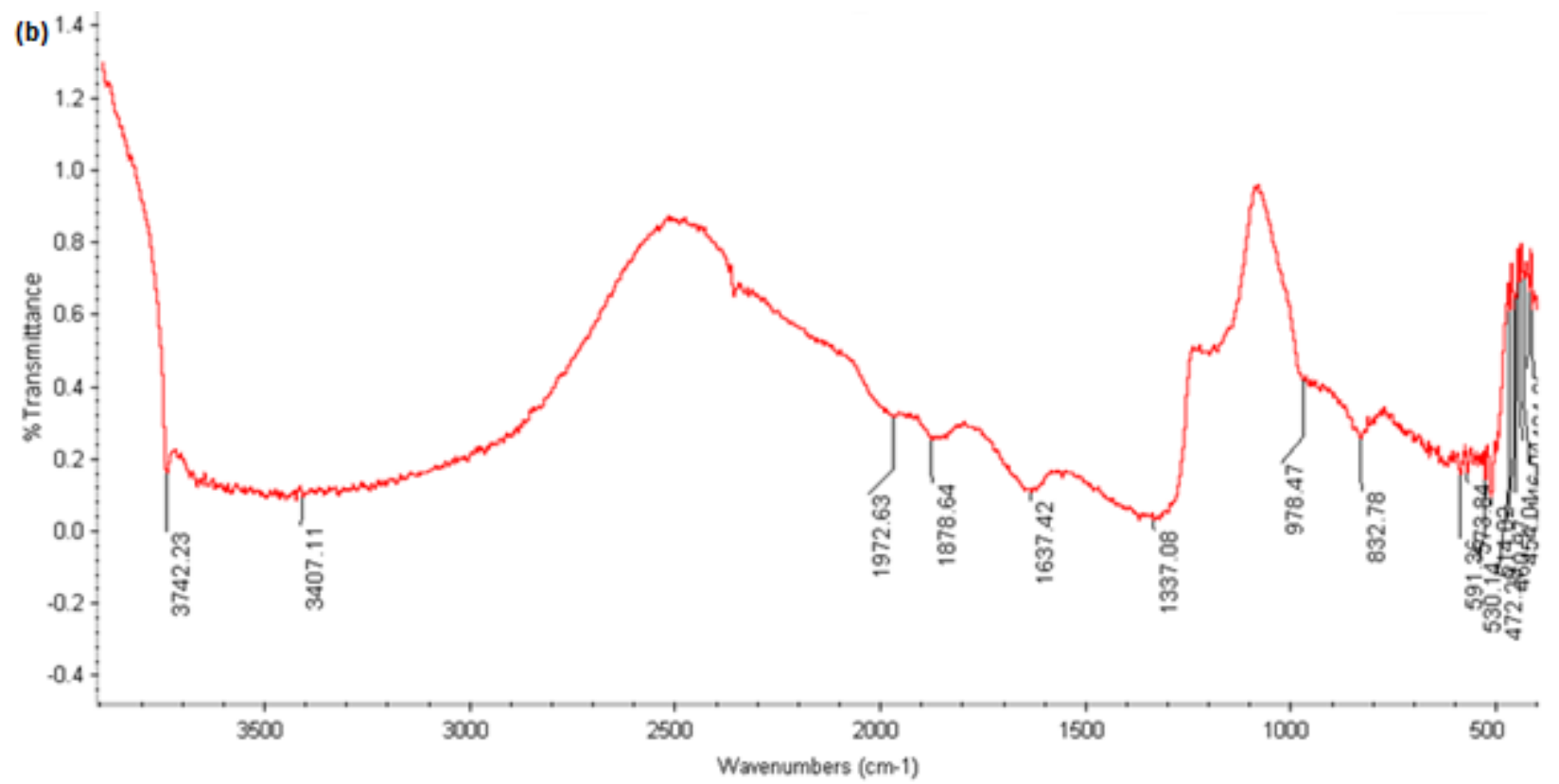

Figure 10: Diffuse Reflectance IR spectra of (a) blank silica, (b) 0.5(mol)\% $\mathrm{Cr}^{-\mathrm{SiO}_{2}} \mathrm{systems}$ Thus, based on the above literature and experimental data it is clear that the $\mathrm{Cr}^{6+}$ loaded silica system is producing reactive electron hole pairs upon light irradiation. Usually, in titania based systems, generation of reactive hydroxyl radicals and oxygen species takes place by reacting surface hydroxyl groups and atmospheric oxygen with photo generated electrons and holes respectively. Similarly, according to the hydroxyl radical experiments carried out for our 0.5(mol)\% Cr loaded silica sample, a fluorescence peak around $426 \mathrm{~nm}$ provides evidence for hydroxyl radical generation during the photocatalytic reaction (figure 7). However, the active site is localized, and all the chemical steps must take place rapidly at that site. Therefore, photo generation of reactive electron and holes in quantum sites of $\mathrm{Cr}-\mathrm{O}$, generate positively charged holes, which must react with surface hydroxyl groups present on the silica surface producing reactive hydroxyl radicals. These hydroxyl radicals may be involved in oxidation of acetaldehyde in the presence of oxygen to carry out complete oxidation to produce carbon dioxide. 


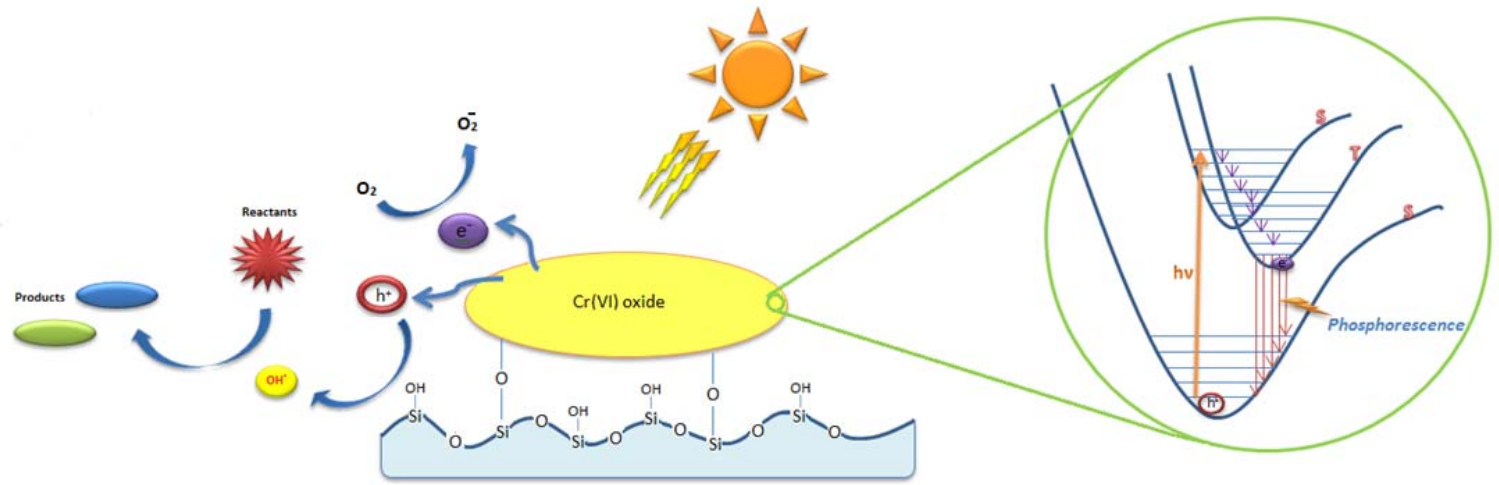

Figure 11: Proposed mechanism of photocatalytic activity.

\section{Summary}

The photocatalytic oxidation ability of chromium loaded silica systems were prepared and studied to better understand localized nature of photocatalysis. The prepared $0.5(\mathrm{~mol}) \% \mathrm{Cr}-\mathrm{SiO}_{2}$ system shows interesting visible and UV light activities towards acetaldehyde degradation. Even though, semiconducting titania based systems are known as successful photocatalytic materials, insulating silica based systems showed higher oxidation abilities towards complete oxidation of acetaldehyde. Such direct comparison has not been reported before. According to the reported literature, most of the silica based systems were successful for either partial oxidation of organic materials or other reactions, such as polymerization, metathesis reactions, etc. ${ }^{[7]}$

Moreover, the structure and the mechanisms which govern the photocatalysis are compared separately for the chromium loaded titania system as well as for the silica based system. Hydroxyl radical generation studies further support the proposed localized electron-hole pair generation at highly dispersed chromium oxide photo active quantum sites.

\section{Acknowledgement}


The research on which this paper is based was supported by the KSU Targeted Excellence Program and partially supported by M2 Corporation through the U.S. Marines.

\section{References}

1. Coronado, J.M.; Maira, A.J.; Conesa, J.C.; Yeung, K.L.; Augugliaro, V.; Soria, J., EPR Study of the Surface Characteristics of Nanostructured $\mathrm{TiO}_{2}$ under UV Irradiation, Langmuir, 2001, 17, 5368-5374

2. Anpo, M.; Applications of titanium oxide photocatalysts and unique second-generation $\mathrm{TiO}_{2}$ photocatalysts able to operate under visible light irradiation for the reduction of environmental toxins on a global scale, Stud. Surf. Sci. Catal, 2000, 130, 157-166

3. Liang, Y. T.; Vijayan, B.K.; Gray, K.A.; Hersam, M.C., Minimizing Graphene Defects Enhances Titania Nanocomposite-Based Photocatalytic Reduction of $\mathrm{CO}_{2}$ for Improved Solar Fuel Production, Nano Lett., 2011, 11, 2865-2870

4. Kudo, A., Photocatalysis and solar hydrogen production, Pure Appl. Chem., 2007, 79, 11, 1917-1927

5. Wang, J.; Uma, S.; Klabunde K.J., Visible light photocatalysis in transition metal incorporated titania-silica aerogels, Applied Catalysis B: Environmental, 2004, 48 151154

6. Yoshida, H.; Active sites of silica-based quantum photocatalysts for non-oxidative reactions, Catalysis Surveys from Asia, 2005, 9, 1

7. Yoshida, H.; Silica-based quantum photocatalysts for selective reactions, Current Opinion in Solid State and Materials Science, 2003, 7, 435-442

8. Yamashita, H.; Yoshizawa , K.; Ariyuki, M.; Higashimoto,S.; Che, M.; Anpo, M., Chem. Commun., 2001, 435-436

9. Linxiang, L.; Abe, Y.; Nagasawa, Y.; Kudo, R.; Usui, N.; Imai, K,; Mashino, T.; Mochizuki, M. and Miyata, N, An HPLC assay of hydroxyl radicals by the hydroxylation reaction of terephthalic acid, Biomed. Chromatogr., 2004, 18, 470-474

10. Hirakawa, T.; Nosaka, Y., Properties of $\mathrm{O}_{2}{ }^{--}$and $\mathrm{OH}^{*}$ Formed in $\mathrm{TiO}_{2}$ Aqueous Suspensions by Photocatalytic Reaction and the Influence of $\mathrm{H}_{2} \mathrm{O}_{2}$ and Some Ions, Langmuir, 2002, 18, 3247-3254

11. Šnyrychová, I.; Hideg, E., First Application of Terephthalate as a Fluorescent Probe for Hydroxyl Radicals in Thylakoid Membranes, Springer, 2008, 1553-1556.

12. Davis; A.P.; Huang, C. P., Effect of Cadmium Sulfide Characteristics on the Photocatalytic Oxidation of Thioacetamide, Langmuir, 1991, 7, 709-713

13. Koshitani, N,; Sakulkhaemaruethai, S.; Suzuki, Y,; Yoshikawa, S.; Preparation of mesoporous titania nanocrystalsusing alkylamine surfactant templates, Ceramics International, 2006, 32, 819-824 
14. Davydov, L.; Reddy, E.P.; France, P.; Smirniotis, P.G., Transition-Metal-Substituted Titania-Loaded MCM-41 as Photocatalysts for the Degradation of Aqueous Organics in Visible Light, Journal of Catalysis, 2001, 203, 1, 157-167.

15. Jagtap, N.; Bhagwat, M.; Awati, P.; Ramaswamy, V.; Characterization of nanocrystalline anatase titania: an in situ HTXRD study, Thermochimica Acta, 2005, 427, 37-41

16. Hou, J.; Cao, R.; Wang, Z.; Jiao,S.; Zhu, H., Chromium-doped bismuth titanate nanosheets as enhanced visible-light photocatalysts with a high percentage of reactive $\{110\}$ facets, J. Mater. Chem., 2011, 21, 7296-7301,

17. Dvoranová, D,; Brezová, V.; Mazúra, M.; Malati, M.A., Investigations of metal-doped titanium dioxide photocatalysts, Applied Catalysis B: Environmental, 2002, 37, 91-105

18. Weckhuysen, B.M.; Schoonheydt, R.A.; Recent progress in diffuse reflectance spectroscopy of supported metal oxide catalysts, Catal. Today, 1999, 49, 441

19. Weckbuysen, B.M.; De Ridder, L.M.; Schoonheydt, R.A.; Quantitative Diffuse Reflectance Spectroscopy Study of Supported Chromium Catalysts, J. Phys. Chem., 1993,97, 4156-4163

20. Bensalem, A.; Weckhuysen, B.M.; Schoonheydt, R.A.; In Situ Diffuse Reflectance Spectroscopy of Supported Chromium Oxide Catalysts: Kinetics of the Reduction Process with Carbon Monoxide, J. Phys. Chem. B, 1997, 101, 2824-2829

21. Weckhuysen, B.M.; Verberckmoes, A.A.; Buttiens, A.L.; Schoonheydt, R.A., Diffuse Reflectance Spectroscopy Study of the Thermal Genesis and Molecular Structure of Chromium-Supported Catalysts, J. Phys. Chem., 1994,98, 579-584

22. Moisii, C.; Deguns, E.W.; Lita, A.; Callahan, S.D.; van de Burgt, L.J.; Magana, D.; Stiegman, A.E.; Coordination Environment and Vibrational Spectroscopy of Cr(VI) Sites Supported on Amorphous Silica, Chem. Mater, 2006, 18,17,3965-3975.

23. Cejka, J.; Corma, A.; Zones, S.; Zeolites and catalysis, synthesis, reactions and applications, Wiley-VCH:Weinheim, 2010, 1, 714

24. Climate Change: The Role of Cities, United Nations Environment Programme (UNEP), 2009

25. Lim, S.H.; Phonthammachai, N.; Pramana, S.S.; White, T.J.; Simple Route to Monodispersed Silica-Titania Core-Shell Photocatalysts, Langmuir, 2008, 24, 6226-6231

26. Barreto, J.C.; Smith, G.S.; Strobel, N.H.P.; McQuillin, P.A.; Miller, T.A., terephthalic acid: A dosimeter for the detection of hydroxyl radicals in vitro, Life Sciences, 1995, 56, 4, 89-96.

27. Hazedcamp, M.F.; Blasse, G., A Luminescence Spectroscopy Study on Supported Vanadium and Chromium Oxide Catalysts, J. Phys. Chem., 1992, 96, 3442-3446 
Supporting Information

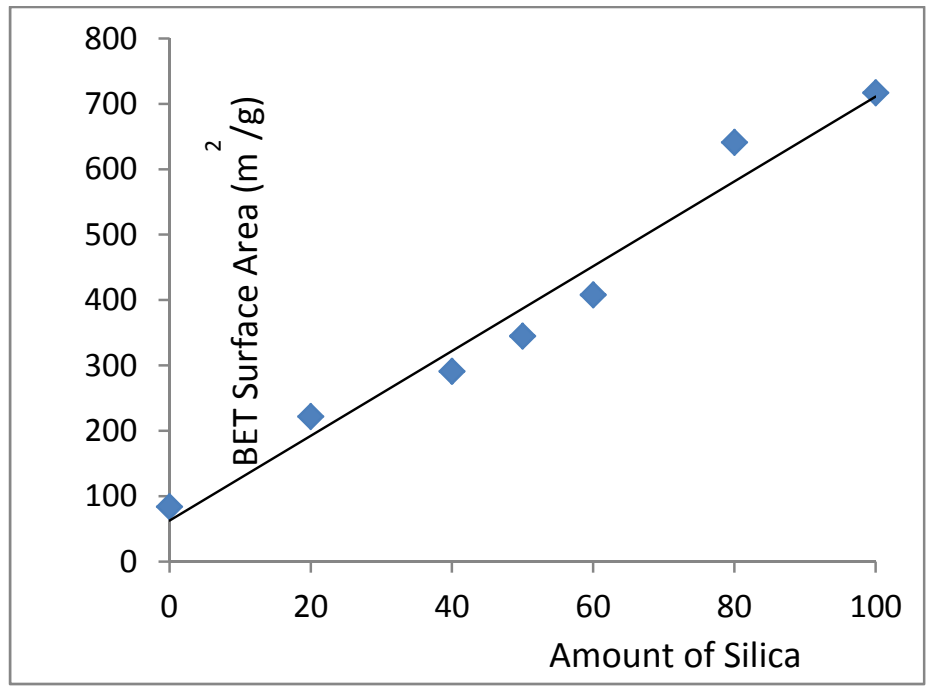

Figure S1: Increase in the effective surface area with increased amounts of silica

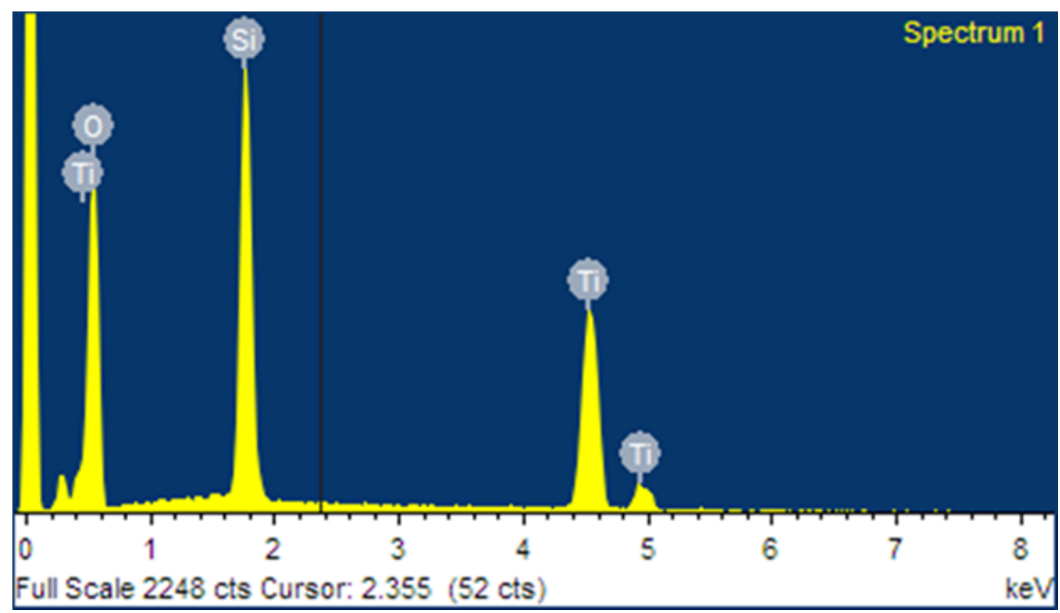

Figure S2: EDS Elemental analysis of $0.5(\mathrm{~mol}) \% \mathrm{Cr}^{-} \mathrm{SiO}_{2}$ 